\title{
Anomalous stability of U(IV) species in sulfate-bearing hydrothermal solutions
}

Migdisov, A.'; VAN HARTESVELDT, N...2, KALINTSEV A. ${ }^{\prime 3}$, NisBet, H..$^{\prime 4}$, AlCORN, C.', STRZELECKI A.C.', RAM R. ., Boukhalfa, H.', XU, H.', GABITOV, R.', BRUGGER, J. ${ }^{.}$, EtSChMAnN, B . ${ }^{3}$, JOVE-COLON, C., MATteO, E.N. ${ }^{s}$, CAPORUSCIO, F.A.', ROBACK, R.', AND WHITE, J.'

Los Alamos National Laboratory, USA (artas@lanl.gov); Mississippi State University, USA; Monash University, Australia; 'McGill University, Canada; 'Sandia National Laboratory, USA

Conventional wisdom suggests that the behavior of uranium in hydrothermal systems is mostly redox-driven and assumes mobilization of this element by aqueous solutions at oxidizing conditions and its complete immobilization when U-bearing solutions meet reducing geochemical barriers. Recently we have challenged this assumption by demonstrating that aqueous mobility of $\mathrm{U}^{4+}$ could be comparable to that of $\mathrm{U}^{\circ+}$ in acidic chloride-rich solutions at $\mathrm{T}>250{ }^{\circ} \mathrm{C}$. The factor limiting implications of $\mathrm{U}(\mathrm{IV})$ chloride transport in natural systems is the fact that these complexes only contribute significantly to total dissolved $\mathrm{U}$ at $\mathrm{pH}$ values below $2.5-2.7$. However, besides chloride, other anionic ligands are also known to be present in natural hydrothermal solutions. Among them, sulfate has been documented as one of the most prevalent species and the goal of this study is to evaluate the stability of U(IV) sulfate complexes at elevated temperatures.

The experiments were performed at $200-350{ }^{\circ} \mathrm{C}$, primarily using the solubility autoclave technique (dissolution of $\mathrm{UO}_{2}$ in sulfate-bearing solutions) in systems with their fugacity of oxygen controlled by $\mathrm{Ni} / \mathrm{NiO}$ and $\mathrm{Co} / \mathrm{CoO}$ solidstate redox buffers. In addition, qualitative confirmation of the results obtained from the solubility experiments have been made using in situ XAS and Raman spectroscopy.

The data collected suggest anomalously high stability of sulfate complexes of U(IV) at temperatures above $250{ }^{\circ} \mathrm{C}$ and $\mathrm{pH}$ as high as 5 . The complex responsible for the high U(IV) solubility was identified as $\mathrm{USO}_{4}(\mathrm{OH})_{2}$; formation constants for this species has been determined. Species distribution suggested by these data at $\mathrm{pH}=5$ and $350{ }^{\circ} \mathrm{C}$ is shown in the figure below.

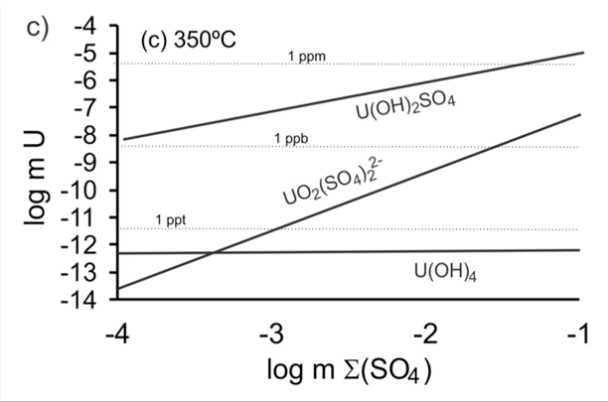

